\title{
Kajian Tingkat Kepuasan Pengguna Jalur Penyeberangan Orang (JPO) pada Central Business District (CBD) Surabaya
}

\section{Study of User Satisfaction Level of Crossing People (JPO) at the Central Business District (CBD) Surabaya}

\author{
Amanda Ristriana Pattisinai ${ }^{1}$, Fitri Rohmah Widayanti ${ }^{1}$, Feriza Nadiar ${ }^{1}$ \\ ${ }^{1}$ Jurusan Teknik Sipil, Fakultas Teknik, Universitas Negeri Surabaya, Jln. Ketintang Surabaya. \\ Email : amandaristriana@unesa.ac.id
}

\begin{abstract}
Abstrak
Berjalan sangat penting untuk mengakses transportasi umum. Sebelumnya, menyelidiki kepuasan berjalan dilakukan dengan skema nyata. Tetapi sekarang pejalan kaki tidak hanya dilihat sebagai orang yang menggunakan fasilitas ini setiap hari. Melalui penilaian pengguna Jalur Penyeberangan Orang (JPO), kita dapat memahami faktor mana yang lebih (atau kurang) penting dan signifikan. Elemen-elemen yang dibahas dalam penelitian ini adalah elemen kepuasan berjalan, yaitu keselamatan, keamanan, kenyamanan, kontinuitas, kenyamanan, koherensi sistem, dan daya tarik. Untuk mengeksplorasi ini, kami mensurvei Jalan Basuki Rahmad, Surabaya, Indonesia sebagai Central Business District (CBD) ( $N=120)$. Metode yang digunakan adalah Importance - Performance Analysis (IPA) yang merupakan ukuran tingkat kepuasan layanan yang masuk kuadran pada peta Importance Performance Matrix. Dalam metode ini, perlu untuk mengukur tingkat kesesuaian untuk mengetahui seberapa besar pengguna merasa puas dengan kinerja jembatan penyeberangan. Faktor yang paling membuat pengguna tidak puas adalah B2 yaitu lampu yang menyala di malam hari, diikuti oleh D1 (pegangan tangan di Jembatan Pedestrian yang mudah dijangkau dan tidak berkarat) dan D5 (Bangunan yang dapat mengurangi getaran saat kendaraan melaju kencang) diatasnya.
\end{abstract}

Kata Kunci: JPO, Kepuasan, IPA, Matrix, Pejalan Kaki, CBD

\begin{abstract}
Walking is very important to access public transportation. Furthermore, for the sake of satisfaction, walking is carried out clearly. Only now pedestrians are not only seen as people who use this facility every day. Through the People Crossing Path (JPO) user assessment, we can consider which factors are more (or less) important and significant. The elements discussed in this study are elements of walking satisfaction, namely safety, security, comfort, continuity, comfort, coherence systems, and attractiveness. To discuss this, we survey Jalan Basuki Rahmad, Surabaya, Indonesia as the Central Business District (CBD) $(N=120)$. The method used is Importance - Performance Analysis (IPA) which is a measure of the level of service satisfaction that is included in the quadrant on the map of the Importance of Performance Matrix. In this method, it is necessary to measure the level of conformity to find out how much the user is satisfied with supporting the crossing bridge. The factor that makes users most dissatisfied is B2, the lights that turn on at night, followed by D1 (handrails on the Pedestrian Bridge that are easily accessible and not rusty) and D5 (Buildings that can repair when a vehicle is speeding) need it
\end{abstract}

Keywords:JPO, Satisfaction, IPA, Matrix, Pedestrian, CBD .

\section{PENDAHULUAN}

Central Business District (CBD), juga disebut "central area" di Eropa dan "downtown" di Amerika Utara, menggambarkan dinamisnya perkembangan ekonomi yang cepat dan seringkali dipandang sebagai tanda kemakmuran sebuah kota (Peng et all, 2020). Kota bisa bergerak menuju pada konsep sentralitas tinggi pada kegiatan sektor ekonomi tersier, seperti bisnis, komersial, keuangan dan kegiatan konsultasi, seperti yang 
pertama kali diperkenalkan secara konseptual oleh Ernest W. Burgess pada tahun 1920-an (Birch, 2009) dan telah lama diselidiki oleh para peneliti di seluruh dunia.

Dalam beberapa dekade terakhir, penelitian terutama difokuskan pada revitalisasi dan pembangunan kembali kawasan CBD (Wachs, 2013; Wagner, 2014; GiustiandMaraschin, 2017). Hasilnya, ide baru dari "kawasan CBD yang sehat" adalah penggunaan lahanCBD menunjukkan perkembanganyang berkelanjutan, ditandai dengan kepadatan bangunan yang lebih tinggi, aksesibilitas transportasi yang lebih baik, walkabilitas yang semakin baik, sarana prasarana penunjang seperti jalur penyeberangan orang (JPO), halte, dan terminal yang ramah pejalan kaki, dan mix-use land use (Filionetal., 2004; Park, 2007; Birch, 2009).

Berjalan kaki saat ini merupakan moda transportasi penting di negara-negara berkembang (Dong, 2019). Namun demikian, infrastruktur pejalan kaki yang tidak memadai telah memaksa orang untuk beralih ke moda transportasi lain. Tidak hanya infrastruktur pejalan kaki yang terus diremehkan dalam perencanaan transportasi umum dan pengembangan kebijakan secara luar biasa di Asia Tenggara Mateo-babiano, 2016; Mateo-babiano et all., 2016) tetapi juga kebutuhan pejalan kaki tetap menjadi perhatian yang paling tidak diperhatikan oleh masyarakat.

Selain itu, lebih dari seperlima dari populasi pengguna jalan yang meninggal setiap tahun, bukannya pengendara mobil, motor atau bahkan sepeda, tetapi mereka adalah pejalan kaki. Meskipun kematian dan cedera pejalan kaki yang sering terjadi di banyak lokasi meningkat setiap tahun, keselamatan pejalan kaki masih belum mendapatkan perhatian yang tepat (Lakhotia et all., 2019; Yannis et all., 2007; Corppola dan Golombek, 2018).

Pejalan kaki menjadi tidak tertarik menggunakan JPO bukan hanya karena tidak merasa aman, tetapi juga karena desain JPO yang tidak bersahabat ini, para pejalan kaki sering kali tidak menggunakannya dan malah menyeberang jalan di bawahnya. Pejalan kaki membuat keputusan berdasarkan lingkungan mereka: jika perilaku mereka berisiko, sering kali itu akibat infrastruktur yang tidak nyaman atau tidak memadai. Jarak tambahan yang harus dilalui pejalan kaki bila melalui JPO, tidak hanya menciptakan penghalang fisik bagi pejalan kaki yang tidak dapat menaiki tangga atau landai yang curam (disabel), tetapi juga menambah waktu dan upaya ekstra yang pasti akan dihindari oleh pejalan kaki dengan hanya menyeberang melalui lalu lintas dibawah JPO. Parahnya, lokasi hunian angkutan umum selalu tidak jauh dari jembatan penyeberangan.Sehingga seringkali terjadi konflik antara lalu lintas kendaraan bermotor, angkutan umum yang berhenti, dan pejalan kaki.

Meskipun berjalan sangat penting untuk mengakses transportasi umum, pengetahuan tentang perilaku pengguna dapat membantu memahami kebutuhan mereka. Diharapkan bahwa menciptakan lingkungan jembatan pejalan kaki berdasarkan pada apa yang mereka butuhkan adalah poin penting untuk keberhasilan kepuasan berjalan (Kim et all., 2014; Golias et all., 2004; Pešic et all., 2016). Kepuasan pengguna jembatan penyeberangan adalah penting karena menenangkan jalan yang dialami oleh pejalan kaki lebih mungkin untuk disukai lagi di lain waktu, dan diteruskan sebagai perilaku yang berkelanjutan dilakukan (Iamtrakul dan Zhang, 2015).

Di Surabaya, JPO telah lama hadir di tengah aktivitas warga, terutama di kawasan CBD seperti Jalan Basuki Rahmad yang memiliki tiga jembatan penyeberangan disepanjang jalan ini. Meski demikian, walaupun JPO ini sudah disediakan oleh pemerintah kota, JPO ini tidak menjadi pilihan pejalan kaki yang populer.

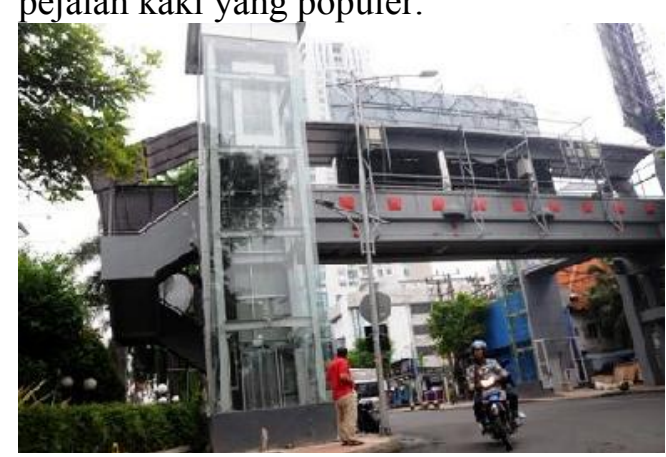

Gambar 1. JPO pada Kawasan CBD di Jalan Basuki Rahmat Surabaya

Berdasarkan hal tersebut, mengeksplorasi kepuasan berjalan melalui penilaian pengguna JPO adalah subjek yang sangat penting untuk diteliti. Penggunaan (IPA) adalah untuk menganalisis tingkat kepuasan layanan yang masuk kuadran pada peta Importance Performance Matrix. Metode ini untuk menentukan tingkat kepuasan pelanggan dengan kinerja jembatan penyeberangan, sehingga kemudian dapat dirumuskan strategi yang paling tepat untuk meningkatkan walkabilitas pada kawasan CBD di Surabaya.

\section{METODE PENELITIAN}

Tujuan dari penelitian ini adalah untuk menyelidiki kepuasan pengguna tentang fasilitas JPO dengan menggunakan variabel. Data yang diperoleh 
kemudian diolah menggunakan analisis kuadran dan analisis deskriptif dengan persentase masing-masing variabel penelitian yang akan diteliti. Pengumpulan data dilakukan dengan menyebarkan kuesioner kepada 120 responden. Dalam penelitian ini, pengambilan sampel penelitian adalah metode random sampling. Metode ini sangat tepat digunakan untuk penelitian yang jumlah populasinya tidak diketahui (tidak stabil).

Penggunaan metode IPA adalah untuk menganalisis kepuasan layanan yang memasuki kuadran pada peta Importance Performance Matrix. Dalam metode ini, perlu untuk mengukur tingkat kesesuaian dan mengetahui seberapa banyak pelanggan puas dengan kinerja perusahaan, dan seberapa banyak penyedia layanan mengetahui apa yang diinginkan pelanggan untuk layanan yang mereka berikan.

Penelitian ini dilakukan untuk menganalisis kepuasan konsumen dengan fasilitas fasilitas Jembatan Pejalan Kaki yang berlokasi di Jalan Jendral Basuki Rahmat. Hasil analisis diperoleh dengan menyebarkan kuesioner kepada pengguna jembatan penyeberangan di sepanjang ruas jalan. kuesioner berisi indikator kinerja layanan jembatan pejalan kaki yang kemudian dinilai oleh pengguna jembatan pejalan kaki. dari analisis ini, kita akan mendapatkan beberapa indikator yang memengaruhi kepuasan pengguna jembatan penyeberangan yang belum tersedia dengan baik, yang dapat diperbaiki sehingga mereka dapat meningkatkan layanan jembatan penyeberangan. Indikator yang digunakan telah ditunjukkan di bawah ini.

Tabel 1. Importance Performance Analysis Indicators

\begin{tabular}{lll}
\hline No & Code & IPA Indicators \\
\hline 1 & A1- A2 & Safety \\
2 & B1- B2 & Security \\
3 & C1 & Convinience \\
4 & D1- D9 & Comfort \\
5 & E1 & System coherence \\
6 & F1 & Attractiveness \\
\hline
\end{tabular}

\section{HASIL DAN PEMBAHASAN}

Penelitian ini dilakukan untuk menganalisis kepuasan pengguna dengan fasilitas JPO yang berlokasi di Jalan Jendral Basuki Rahmat. Hasil analisis diperoleh dari data kuesioner yang dibagikan kepada pengguna JPO di sepanjang ruas jalan. Kuesioner berisi indikator kinerja layanan JPO yang kemudian dinilai oleh pengguna JPO. Dari analisis ini, kita akan mendapatkan beberapa indikator yang memengaruhi kepuasan pengguna JPO yang belum tersedia dengan baik, yang dapat diperbaiki sehingga dapat meningkatkan layanan JPO.

Di Jembatan Penyeberangan Gramedia, sebagian besar kegiatan perjalanan berasal dari 35\% perumahan dan $60 \%$ kantor di dalam kabupaten. Karena lokasinya sendiri di tengah Kawasan Pusat Bisnis (CBD), jembatan penyeberangan ini kemungkinan digunakan oleh karyawan. Berdasarkan matriks IPA pada gambar 2, terlihat bahwa indikator yang dianggap penting bagi pengguna Jembatan Pedestrian tetapi tidak sesuai dengan harapan pengguna Jembatan Pedestrian di Gramedia adalah indikator 4 (B2) dan 6 (D1), yang merupakan penerangan. pada malam hari dan pegangan tangan di Jembatan Pedestrian yang mudah dijangkau pengguna dan tidak berkarat.

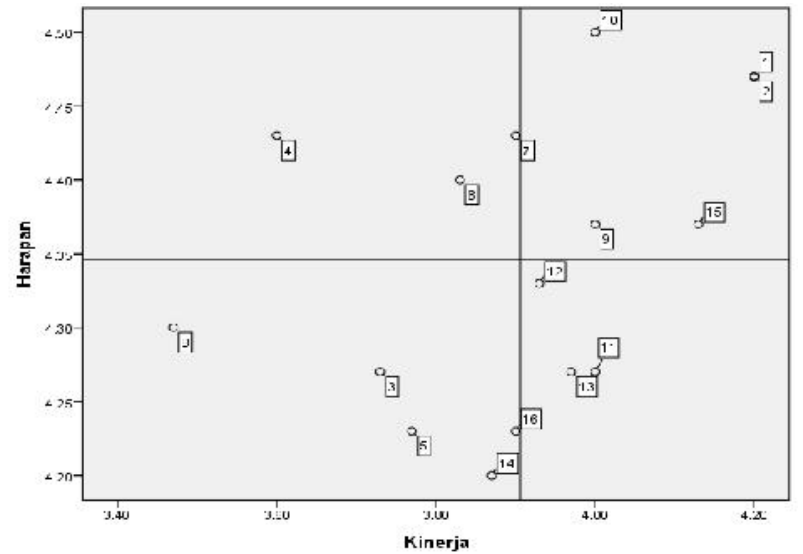

Gambar 2. IPA Matrix JPO Gramedia

Sementara berdasarkan kuesioner kepada 25 responden pejalan kaki di JPO Ranch Market, 40\% responden (10 responden) pejalan kaki memiliki tujuan untuk makan, berbelanja, dan bertemu. Jembatan penyeberangan ini diperlengkapi dengan lift, sehingga siapapun termasuk pejalan kaki yang disabel dapat mengaksesnya. Matriks pada gambar 3 menunjukkan bahwa ada lima indikator yang dirasa kurang optimal bagi pengguna JPO. Yaitu indikator 4 (B2) Pencahayaan di malam hari, indikator 8 (D3) Papan iklan yang tidak mengganggu pandangan pengguna untuk melihat situasi turun, indikator 9 (D4) Ukuran pagar pembatas yang sesuai dan indikator 10 (D5) Bangunan yang dapat mengurangi getaran ketika kendaraan melaju kencang di atasnya. 


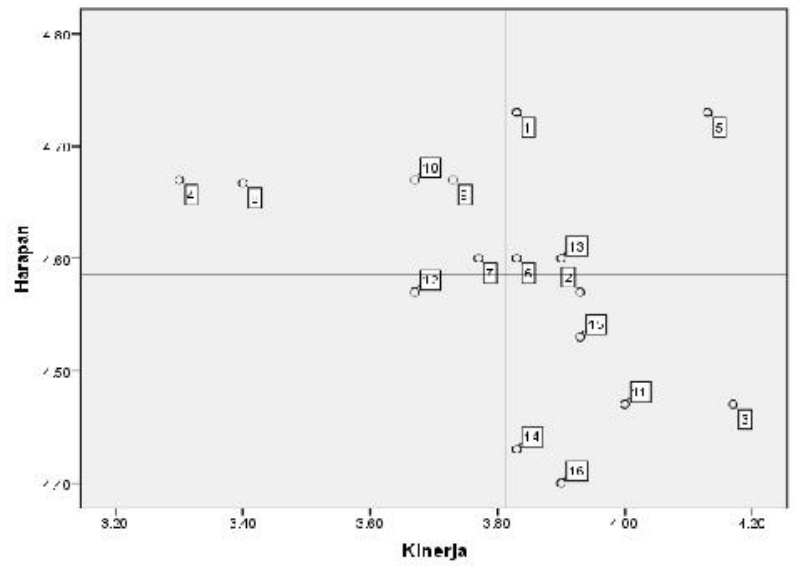

Gambar 3. IPA Matrix JPO Ranch Market

Selanjutnya, pejalan kaki yang berjalan kaki dari Tunjungan Plaza sering berhenti untuk menikmati kegiatan makan dan minum. Penyewa dan pedagang yang menyediakan makanan segar selalu memberikan daya tarik bagi pejalan kaki. Matriks pada gambar 4 menunjukkan bahwa ada tiga indikator yang dirasa kurang optimal untuk Pengguna JPO Tunjungan Plaza . Indikatorindikator ini adalah indikator 4 (B2) Pencahayaan di malam hari, indikator 6 (D1) Pegangan tangan pada JPO yang mudah dijangkau dan tidak berkarat, Indikator 10 (D5) bangunan yang dapat mengurangi getaran ketika kendaraan melaju kencang di atasnya.

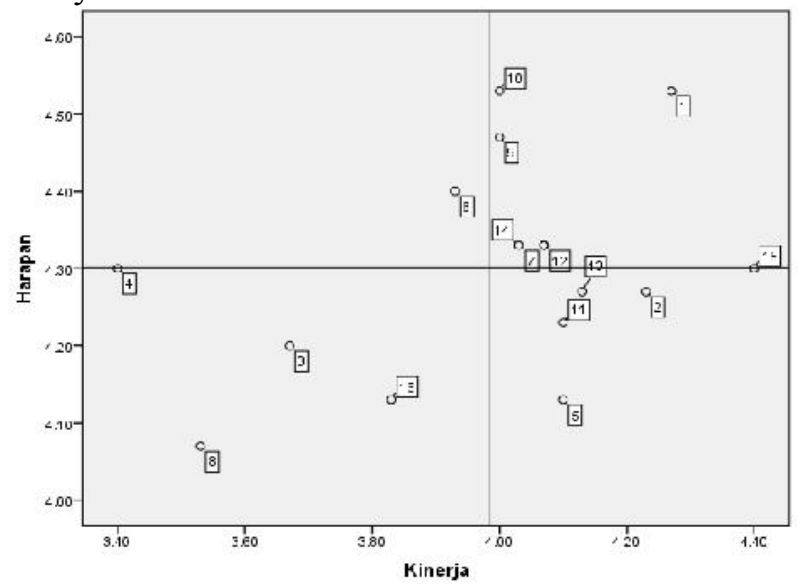

Gambar 4. IPA Matrix JPO Tunjungan Plaza

Berdasarkan hasil analisis kuadran diketahui bahwa indikator yang dibutuhkan oleh pengguna JPO tetapi kondisi fasilitas lapangan belum terpenuhi adalah pencahayaan lampu di malam hari. Hal ini didukung juga berdasarkan hasil survei kondisi di lapangan yang menunjukkan bahwa parameter pencahayaan ada tetapi tidak optimal, dan berdasarkan hasil wawancara diketahui bahwa kondisi ini terjadi terutama pada malam hari.

\section{SIMPULAN}

Elemen-elemen yang dibahas dalam penelitian ini adalah elemen kepuasan berjalan, yaitu keselamatan, keamanan, kenyamanan, kontinuitas, kenyamanan, koherensi sistem, dan daya tarik. Untuk mengeksplorasi ini, kami mensurvei Jalan Basuki Rahmad, Surabaya, Indonesia $(\mathrm{N}=120)$. Metode (IPA) merupakan ukuran tingkat kepuasan layanan yang masuk kuadran pada peta Importance Performance Matrix. Dalam metode ini, perlu untuk mengukur tingkat kesesuaian untuk mengetahui seberapa besar pengguna merasa puas dengan kinerja jembatan penyeberangan. Kami menemukan bahwa faktor yang paling membuat pengguna tidak puas adalah B2 yang menyala di malam hari, diikuti oleh D1 (pegangan tangan di Jembatan Pedestrian yang mudah dijangkau dan tidak berkarat) dan D5.

\section{REFERENSI}

Birch, E. L., 2009, "Downtown in the "new American city". Annal. Am. Acad. Politic. Soc. Sci.626(1),134-153.

Filion, P., Hoernig, H., Bunting, T., Sands, G., 2004, "The successful few: healthy downtowns of small metropolitan regions". $J$. Am. Plann. Associat. Vol 70 No. 3,328-343.

Giusti, C., Maraschin, C., 2017, "Downtown revitalization and urban space: acase study in downtown Bryan, Texas”. Citie sVol 60, 5063.

G. Yannis, J. Golias, and E. Papadimitriou, "Modeling Crossing Behavior and Accident Risk of Pedestrians," no. November, pp. 634644, 2007.

I. Mateo-babiano, "Pedestrian' $s$ needs matters : Examining Manila's walking environment," vol. 45, pp. 107-115, 2016.

I. Mateo-babiano, H. Tang, S. Conejos, and E. H. W. Chan, "A63 Is an Active City a Healthier City for the Elderly? Examining Hong Kong ' s Active Transport Planning and SOT-14 Active Travel \& Health," J. Transp. Heal., vol. 3, no. 2, pp. S42-S43, 2016.

Park, S., 2007. Prescriptive plans for a healthy central business district: seattle downtown design,1956-1966. Pacific North west Quart. Vol 98 No.3,107-114.

Peng, Le-Fang et. all., 2020, "Planning and implementation of underground space in Chinese central business district (CBD): Acase of Shanghai Hongqiao CBD". Tunnelling and Underground Space Technology “, Tunnelling and Underground Space Technology. Vol. 95 January 2020. 
Wachs, M., 2013, "Turning cities inside out: transportation and there surgence of downtowns in North America ".Transportation. Vol 40 No. $6,1159-1172$.

Wagner, P., 2014, "New life for American Downtowns?". The 1958 international seminar on urban renewal and the travel of planning ideas in the North Atlantic World. Planning Perspectives. Vol. 29 No. 2,189208. 